\title{
De toekomst van werk: impact van technologie op organisaties (deel 1)
}

\author{
EVA DEROUS, ERIC RIETZSCHEL
}

17 november 2020

Toen we afgelopen najaar een call for papers publiceerden voor een themanummer over de toekomst van werk, konden we niet weten wat er in 2020 allemaal zou veranderen. Reflecties op en speculaties over de toekomst zijn zo oud als de mensheid, en ook beschouwingen over de toekomst van werk zijn niet nieuw. Zulke beschouwingen gaan traditioneel veelal over de effecten van technologie: de uitvinding van allerhande machines, geautomatiseerde productieprocessen, informatie- en communicatietechnologie, digitale media en internet hebben allemaal hun, vaak onverwachte, stempel gedrukt op de manier waarop we werken en ons werk beleven. Ook nu, in een tijdperk waarin het werkende leven voor veel mensen door de coronacrisis is veranderd in een permanente exercitie in digitale vaardigheden (of een permanente confrontatie met het gebrek daaraan), ligt technologie in het hart van speculaties over de toekomst van werk.

'Meanwhile, the poor Babel fish, by effectively removing all barriers to communication between different races and cultures, has caused more and bloodier wars than anything else in the history of creation.'

Douglas Adams (1979), The Hitchhiker's Guide to the Galaxy

Sommige auteurs stellen desalniettemin dat de eenzijdige nadruk op veranderingen en innovatie een vertekend beeld geeft van technologie en de manier waarop deze (onder meer op het werk) wordt ingezet: oude technologieën en materialen worden wereldwijd veel meer en ook veel langduriger ingezet dan we soms denken (Edgerton, 2019). De laatste decennia hebben de ontwikkeling en verspreiding van digitale technologieën echter een dermate hoge vlucht genomen (Cascio \& Montealegre, 2016) dat onderzoek naar, en reflectie op, de toekomst van werk in relatie tot deze nieuwe vormen van technologie van groot belang is. MIT-onderzoekers Brynjolfsson en McAfee (2014) spreken zelfs over het 'tweede machinetijdperk'. Zo is de fictieve 'Babel fish' van sciencefictionauteur Douglas Adams (een visje dat als universele vertaler dient zodra men het in zijn of haar oor stopt) door de opkomst van spraak- en vertaaltechnologie meer realiteit dan fictie geworden: inmiddels is het mogelijk om geschreven en zelfs gesproken tekst in real time te laten vertalen via kleine 'oortjes' die verbonden zijn met draagbare apparaten zoals smartphones. Tegelijkertijd dienen we te erkennen dat het idee op zich ook weer niet nieuw is: filosofen en taalwetenschappers, zoals Warren Weaver, bogen zich reeds in de eerste helft van de twintigste eeuw over dit idee van automatische, door machines gefaciliteerde vertalingen (Weaver, 1949). 
Fictie en (toekomst)dromen zijn dus niet altijd bedrog: sommige ideeën en dromen komen vroeg of laat uit door (bijvoorbeeld) nieuwe technologische mogelijkheden. Net zoals de Babel fish zowel positieve effecten (bijv. mensen uit verschillende culturen dichter bij elkaar brengen) als negatieve effecten (bijv. culturele en andere misverstanden creëren) teweegbrengt, bieden nieuwe digitale technologieën verschillende mogelijkheden voor organisaties die enerzijds positieve, maar anderzijds ook minder fraaie effecten kunnen hebben. Voor organisaties lijken in eerste instantie vaak vooral de mogelijke positieve gevolgen saillant. Digitalisering creëert bijvoorbeeld kansen voor nieuwe ondernemingen en producten. Algoritmes en robots kunnen routinematig, saai of gevaarlijk werk overnemen en dit soms zelfs nauwkeuriger, veiliger en langduriger uitvoeren dan mensen. Bovendien hebben computers, algoritmes en robots geen aandacht, koffiepauzes, vakantie of slaap nodig, hoewel onderhoud en de installatie van updates ook tijd kosten. Adoptie van nieuwe technologieën kan dus voor zowel organisaties als werknemers interessant zijn en grote voordelen met zich meebrengen. Toch brengen de recente technologische ontwikkelingen ook specifieke uitdagingen met zich mee. In dit themanummer over de impact van technologie op organisaties worden deze verschillende uitdagingen van verschillende kanten belicht.

Dat de toekomst van werk onderzoekers ook vandaag de dag bezighoudt, blijkt wel uit het grote aantal bijdragen dat we voor dit themanummer ontvangen hebben: acht artikelen zijn uiteindelijk geaccepteerd voor publicatie. Het themanummer wordt daarom opgesplitst in twee nummers: het laatste nummer van G\&O-jaargang 2020 en het eerste nummer van jaargang 2021. In beide delen van het themanummer komen verschillende uitdagingen, theoretische perspectieven en onderzoeksmethodologieën aan bod. In dit eerste deel staan twee vragen centraal: Hoe beïnvloeden technologische applicaties (zoals robots en algoritmes) de kwaliteit van geleverd werk? En hoe gaan mensen om met technologische ontwikkelingen? Bij deze tweede vraag komt ook de invloed van individuele verschillen op het succes van technologische implementaties aan bod.

\section{Hoe beïnvloeden technologische applicaties de kwaliteit van geleverd werk?}

Een van de meest relevante kenmerken van robots en computers (c.q. algoritmes) is, uiteraard, dat ze verschillende taken van werknemers kunnen overnemen, wat meteen de vraag oproept of ze werknemers ooit volledig zullen (kunnen) vervangen (Brynjolfsson \& McAfee, 2011; McGaughey, 2018). Algoritmes en robots worden reeds ingezet voor het uitvoeren van routinematige taken (zoals het informeren van klanten of het vervoeren en opbergen van materialen), het verrichten van zeer nauwkeurige taken (zoals het uitvoeren van chirurgische ingrepen), het uitvoeren van fysiek en mentaal belastende taken (zoals het assembleren van auto-onderdelen of screenen van cv's) of het overnemen van gevaarlijke taken (zoals het onschadelijk maken van mijnen en andere explosieven). Een belangrijke vraag hierbij is hoe 
technologische applicaties op de werkplek (zoals robots of algoritmes) invloed hebben op de kwaliteit van het geleverde werk en of robots en algoritmes het beter doen dan mensen 'van vlees en bloed'. In een eerste bijdrage bekijken Hiemstra, Cassel, Born en Liem (2020) deze vraag. In het bijzonder bespreken ze hoe machine learning algoritmes werken bij personeelsselectie en vergelijken ze deze toepassing met de traditionele werkwijze van selectiepsychologen. Daarnaast onderzoeken Hiemstra en collega's door middel van een literatuurstudie (periode 2016-2019) of dergelijke algoritmes de belofte van verminderde bias en (indirecte) discriminatie bij selectiebeslissingen waar kunnen maken. Net als mensen blijken ook algoritmes vatbaar voor bias en discriminatie en blijft de basiskennis van selectiepsychologen, naast die van computerwetenschappers, nodig om digitale technologieën te ontwikkelen en de psychometrische kwaliteit van selectie-instrumenten alsmede de impact op sollicitanten te bewaken (Ryan \& Derous, 2019).

\section{Hoe gaan mensen om met technologische ontwikkelingen?}

Dat robots en algoritmes door mensen geprogrammeerd en getraind worden, illustreert de diepe verwevenheid van mens en machine: de dag dat mensen zichzelf geheel en al overbodig gemaakt hebben, zal vermoedelijk nooit aanbreken. Hoezeer de automatisering, robotisering, of algoritmisering van de werkvloer ook voortschrijdt, deze zal altijd worden gekenmerkt door een bepaalde vorm van interactie tussen mensen en hun technologie. Dit brengt ons bij de vraag hoe werknemers met nieuwe technologische ontwikkelingen omgaan, en of er individuele verschillen zijn die het succes van technologische implementaties bepalen. Omdat technologische ontwikkelingen ons confronteren met nieuwe praktische en ethische vragen, kunnen individuele verschillen een aanzienlijke impact hebben op de acceptatie, de implementatie en het gebruik van technologische applicaties in een werkcontext (zie bijv. Nistor, Lerche, Weinberger, Ceobanu, \& Heymann, 2014; Oostrom, Van der Linden, Born, \& Van der Molen, 2013).

Twee individuele verschillen die bijzonder relevant lijken als het gaat om de reacties op nieuwe technologie, zijn leeftijd en opleiding. Er bestaat bijvoorbeeld een hardnekkig en negatief stereotype over oudere werknemers als inflexibel en niet bereid of in staat om nieuwe vaardigheden te verwerven (Kunze, Boehm, \& Bruch, 2013). Over lager-opgeleide werknemers leeft het idee dat technologie hun werk versimpelt of zelfs overbodig maakt, waardoor werk minder zinvol wordt voor hen of ze zelfs geheel uit de arbeidsmarkt dreigen te vallen (Brynjolfsson \& McAfee, 2011, 2014). Zoals bij alle stereotiepe denkbeelden is ook hier de vraag in hoeverre ze de werkelijkheid representeren of juist vertekenen.

In de tweede bijdrage binnen dit themanummer onderzochten Van Vuuren, Peeters, Pareja Diaz en Van Veen (2020) de samenhang tussen 'technostress', duurzame inzetbaarheid en chronologische leeftijd bij medewerkers uit een Nederlandse organisatie in de technische sector. 
Het traditionele, stereotiepe idee dat vooral oudere medewerkers last hebben van technostress (Nimrod, 2018), werd in deze studie beperkt bevestigd. Ook al vinden oudere werknemers het werken met technologie doorgaans complexer dan jongere werknemers, toch was er maar een beperkte invloed van leeftijd op het verband tussen technostress en duurzame inzetbaarheid van oudere medewerkers.

Berkers, Smids, Nyholm en Le Blanc (2020) presenteren, in de derde bijdrage binnen dit themanummer, een kwalitatieve studie naar de invloed van robotisering op betekenisvol werk, en de mate waarin medewerkers en hun leidinggevenden robotisering ervaren als een bedreiging of juist als een kans. Deze studie werd uitgevoerd in acht Nederlandse distributiecentra. In het algemeen bleek de invloed van robotisering negatief te zijn op het vlak van ervaren autonomie, sociale relaties en taakidentiteit van medewerkers. Opvallend: deze negatieve percepties werden in mindere mate vermeld door de directe leidinggevenden en waren dus niet gelijk voor iedereen. Een mogelijke verklaring hiervoor leggen de auteurs bij het (lagere) opleidingsniveau, al halen de auteurs ook andere individuele verschilfactoren aan die nader onderzoek vergen, zoals de mate waarin medewerkers initiatief tonen om zich nieuwe technologische applicaties eigen te maken. We eindigen het eerste deel van dit themanummer met een systematische literatuurstudie van Plomp en Peeters (2020), die studiebevindingen over de effecten van technologische vernieuwing op de algemene kwaliteit van werk en welzijn (periode 2004-2019) in kaart brengt. Deze literatuurstudie toont dat door de invoering van nieuwe technologie de taakeisen voor werknemers inderdaad toenemen, terwijl de mate van ervaren controle afneemt. Deze veranderende taakeisen hangen dan weer negatief samen met het algemene welzijn van medewerkers, terwijl veranderende hulpbronnen (zoals feedback en autonomie) geen eenduidig effect hebben. Op basis van deze literatuurstudie suggereren de auteurs dat gerichte training en individuele verschilfactoren (zoals 'self-efficacy') belangrijk zijn voor een succesvolle implementatie van nieuwe technologische systemen.

\section{Breedte en beperkingen}

De eerste vier artikelen uit dit themanummer over de impact van technologie op organisaties adresseren een scala aan vraagstukken en uitdagingen, en representeren een breed palet aan onderzoeksmethoden, van literatuurstudies (Hiemstra et al., 2020; Plomp \& Peeters, 2020) tot kwalitatief (Berkers et al., 2020) en kwantitatief (Van Vuuren et al., 2020) empirisch onderzoek. Gezamenlijk geven deze artikelen een beeld van de veelzijdige impact van technologische ontwikkelingen op de aard, de organisatie en de beleving van werk. Het tweede deel van dit themanummer (dat dus in 2021 verschijnt) zal het scala aan vraagstukken en uitdagingen verder verbreden en uitdiepen. Een van de onderwerpen die daarbij in verschillende artikelen belicht zal worden, is de mogelijkheid dat technologie kan leiden tot een andere, nieuwe invulling van werk. Ook wordt aandacht besteed aan specifieke, noodzakelijke vaardigheden voor het omgaan met nieuwe technologie, vaardigheden waar mogelijk niet iedere werknemer of organisatie over beschikt. 
Voor beide themanummers dient de kanttekening te worden gemaakt dat een technologische insteek niet alle toekomstige ontwikkelingen op en rond het werk kan omvatten. Ontwikkelingen met betrekking tot (waargenomen) eerlijkheid en rechtvaardigheid, diversiteit en inclusie, veiligheid en gezondheid, en de verschillende verplichtingen en verantwoordelijkheden waar werknemers en werkgevers mee te maken hebben, zullen ook in de toekomst blijven plaatsvinden en daarmee steeds nieuwe stempels drukken op de organisatie en beleving van werk.

Een opvallende afwezige in beide themanummers is bovendien, uiteraard, de enorme impact van de coronacrisis op de organisatie en uitvoering van werk. Zouden we onze call for papers een half jaar later gepubliceerd hebben, dan zou de inhoud van dit themanummer er wellicht geheel anders hebben uitgezien. Artikelen over thuiswerken, samenwerking via digitale media, het combineren (of juist scheiden) van werk- en privéleven als het kantoor alleen nog virtueel bestaat, of zelfs het (door velen gehoopte) einde van de open kantoortuin en de nieuwe inrichting van veilige werkplekken zijn de komende tijd wellicht alsnog te verwachten, maar vallen dus buiten de planning van dit themanummer. De ironie hiervan ontgaat ons niet. Bovendien wijst de huidige situatie ons op de betrekkelijkheid van elke uitspraak en verwachting over de toekomst. Met deze disclaimer over toekomstverwachtingen in gedachten hopen we desalniettemin dat dit themanummer de lezer zal informeren en inspireren. Welke vorm de toekomst van het werk ook aanneemt, feit is dat we dagelijks geconfronteerd worden met nieuwe technologische mogelijkheden en uitdagingen op het werk. Relevante theorievorming en onderzoek zoals gepresenteerd in dit themanummer zijn onmisbaar om organisaties, maar vooral ook de mensen in die organisaties, te helpen deze mogelijkheden en uitdagingen het hoofd te bieden en, waar mogelijk, zelf vorm te geven.

Print

\section{Literatuur}

- Adams, D. (1979). The hitchhiker's guide to the galaxy. New York: Random House.

- Berkers, H. A., Smids, J., Nyholm, S. R., \& Le Blanc, P. M. (2020). Robotisering en betekenisvol werk in distributiecentra: Bedreigingen en kansen. Gedrag \& Organisatie, 33, 324-347.

- Brynjolfsson, E., \& McAfee, A. (2011). Race against the machine: How the digital revolution is accelerating innovation, driving productivity, and irreversibly transforming employment and the economy. Digital Frontier Press.

- Brynjolfsson, E., \& McAfee, A. (2014). The second machine age: Work, progress, and prosperity in time of brilliant technologies. W. W. Norton.

- Cascio, W. F., \& Montealegre, R. (2016). How technology is changing work and organizations. Annual Review of Organizational Psychology and Organizational Behavior, 3, 349-375. https://doi.org/0.1146/annurev-orgpsych-041015-062352 
- Edgerton, D. (2019). The shock of the old (revised edition). London, UK: Profile Books.

- Hiemstra, A. M. F., Cassel, T., Born, M. Ph., \& Liem, C. C. S. (2020). De (on)mogelijkheid van machine learning voor het verminderen van bias en discriminatie bij personeelsbeslissingen. Gedrag \& Organisatie, 33, 279-299.

- Kunze, F., Boehm, S., \& Bruch, H. (2013). Age, resistance to change and job performance, Journal of Managerial Psychology, 28, 7/8, 741760. https://doi.org/10.1108/JMP-06-2013-0194

- McGaughey, E. (2018). Will robots automate your job away? Full employment, basic income, and economic democracy. Centre for Business Research, University of Cambridge. Working Paper no 4. https://doi.org/10.2139/ssrn.3044448

- Nimrod, G. (2018). Technostress: Measuring a new threat to well-being in later life. Aging \& Mental Health, 22(8), 1086-1093. https://doi.org/10.1080/13607863.2017.1334037

- Nistor, N., Lerche, T., Weinberger, A., Ceobanu, C., \& Heymann, O. (2014). Towards the integration of culture into the unified theory of acceptance and use of technology. British Journal of Educational Technology, 45, 36-55. https://doi.org/10.1111/j.14678535.2012.01383.x

- Oostrom, J. K., Van der Linden, D., Born, M. Ph., \& Van der Molen, H. (2013). New technology in personnel selection: How recruiter characteristics affect the adoption of new selection technology. Computers in Human Behavior, 29, 2404-

2415. https://doi.org/10.1016/j.chb.2013.05.025

- Plomp, J. \& Peeters, M. C. W. (2020). De invloed van technologische vernieuwingen op de kwaliteit van werk en welzijn: Een systematische literatuurstudie. Gedrag \& Organisatie, 33, 348-375.

- Ryan, A. M., \& Derous, E. (2019). The unrealized potential of technology in selection assessment. Journal of Work and Organizational Psychology, 35, 85-

92. https://doi.org/10.5093/jwop2019a

- Van Vuuren, T., Peeters, M., Pareja Diaz, S., \& Van Veen, B. (2020). Het verband tussen technostress en duurzame inzetbaarheid: Doet leeftijd ertoe? Gedrag \& Organisatie, 33, 300323.

- Weaver, W. (1949). Translation. Rockefeller Foundation Archives. Retrieved from http://www.mt-archive.info/Weaver-1949.pdf

Boom (c) 2009-2020 Uitgeverij Boom Amsterdam 